\title{
Diamond surface features and metasomatic processes in subcratonic mantle
}

\author{
Yana Fedortchouk ${ }^{1}$, Samantha Perritt ${ }^{2}$, Ingrid L. Chinn ${ }^{2}$ \\ ${ }^{1}$ Dalhousie University, Halifax, Canada, yana@dal.ca \\ ${ }^{2}$ De Beers Exploration, Johannesburg, South Africa, Samantha.Perritt@debeersgroup.com, \\ Ingrid.Chinn@debeersgroup.com
}

\section{Introduction}

Natural diamonds show a large diversity of surface dissolution features, some of which develop in the kimberlite magma during ascent whereas others are inherited from the mantle and are preserved due to diamond enclosure within xenoliths. Such mantle-derived dissolution features reflect conditions associated with diamond-destructive metasomatism and help to shed light on metasomatic processes in the subcratonic mantle. Experiments show that the presence and composition of fluid in kimberlite magmas can also radically change diamond surface features. In this study we examine the distribution of mantle-derived resorption features in four diamond parcels from four different lithologies in the BK1 and AK15 kimberlites (Orapa cluster, Botswana). We apply the results of dissolution experiments conducted at mantle conditions, to predict the nature of metasomatic processes in the subcratonic mantle responsible for diamond growth and partial dissolution. The content and nature of nitrogen defects determined by Fourier transform infrared spectroscopy (FTIR) is used to compare the mantle residence conditions of morphologically different diamond groups.

a.
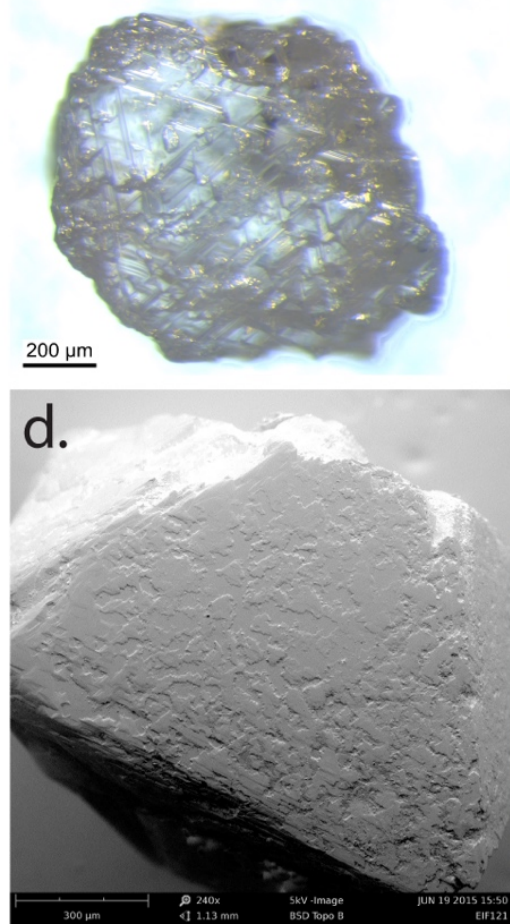

b.
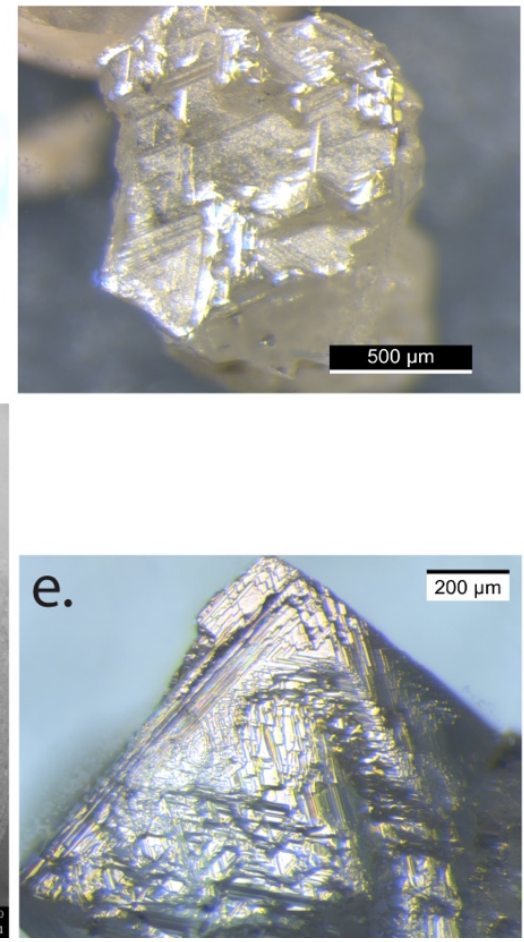

C.
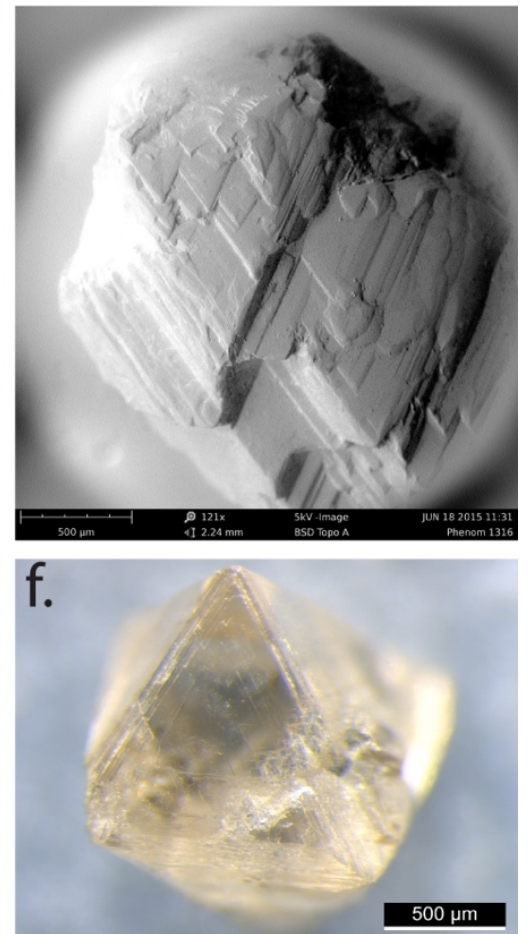

Figure 1: Most common morphological types of mantle-derived resorption on diamonds from BK1 and AK15 kimberlites. a. "complex surface" (MCOM), b. "deep pits", c. step-faced with protrusions (MSF6), d. "islands", e. laminae (MLAM), f. step-faced with laminae (MSF4). 


\section{Diamond samples and mantle resorption groups}

The study uses 802 diamonds $(>0.5 \mathrm{~mm})$ from three kimberlite lithologies in the BK1 pipe and one lithology from the AK15 intrusion (see details in the abstract 11IKC-4582). Diamonds were obtained from reverse circulation drill holes (depths to $160-200 \mathrm{~m}$ ) in each kimberlite lithology and diamonds from each $2-13 \mathrm{~m}$ interval were studied separately. We discriminate diamonds with 1) kimberliteinduced resorption, 2) mantle-derived resorption, 3) mantle resorption overprinted by resorption in kimberlite magma (see abstract 11IKC-4582). Mantle-derived surface features are identified on 263 diamonds, of which 182 diamonds were assigned to a specific morphological group (Fig. 1). While kimberlite-induced resorption styles are uniform in each lithology and unique to this lithology, mantlederived resorption in diamonds from each lithology comprises $\sim 12$ different types (Fig. 1) in similar proportions for the four diamond parcels (Fig. 2). In each parcel, 30-50\% of all diamonds with mantlederived resorption exhibit the same resorption style with deep stepped etch pits (Fig. 1a). Furthermore, this resorption style shows similarities with resorption styles shown in Figs. 1b,c, which may reflect their common origin. Two other resorption types present in each parcel, MSF4 and "laminae" (Fig. $1 \mathrm{e}, \mathrm{f}$ ), formed by thin layering possibly represent another resorption event. The other seven resorption types, including unresorbed octahedral diamonds, represent a very small fraction of the studied diamonds (Fig. 2).
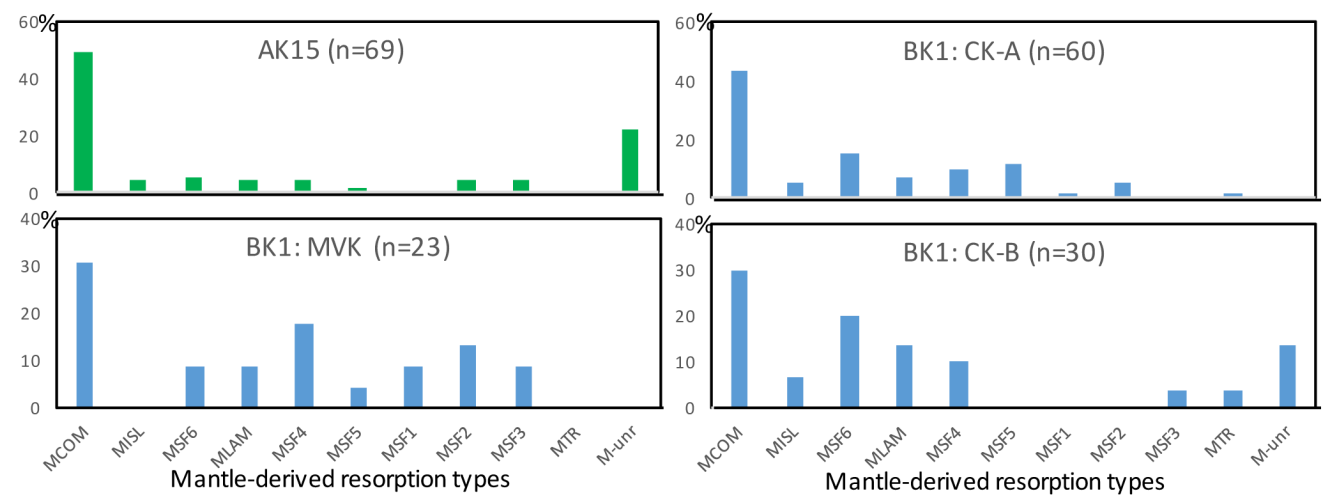

Figure 2: a) Distribution of diamonds between different mantle-resorption groups in AK15 kimberlite and three lithologies from BK1 kimberlite.

Nitrogen content and aggregation state were determined for 636 and 198 diamonds from BK1 and AK15 kimberlites respectively. Our data showed no difference in nitrogen content and aggregation state between diamonds with kimberlite-induced and mantle-derived resorption, or between diamonds with different mantle-derived resorption types (Fig. 3). This may imply a similar degree of disintegration of mantle xenoliths derived from mantle regions with different thermal regimes. Furthermore, different mantle resorption moprhologies were developed on diamonds residing in mantle clusters with different thermal regimes. On the contrary, different kimberlite lithologies seem to sample diamonds from different mantle clusetrs both in terms of thermal regime and nitrogen defects in diamond. Fig. 3 shows a difference in distribution of nitrogen defects in diamonds from the CK-B unit and CK-A and MVK units of BK1. The distribution of nitrogen defects in BK1 and AK15 diamonds is also different.

\section{Diamond-destructive media in the mantle}

We compared the mantle-resorption features of diamonds from BK1 and AK15 to the results of diamond dissolution experiments at mantle pressures and temperatures in $\mathrm{C}-\mathrm{O}-\mathrm{H}$ fluids, $\mathrm{SiO}_{2}$-saturated $\mathrm{C}-\mathrm{O}-\mathrm{H}$ fluids, silica-carbonate melts, and carbonate melts. No mantle-derived dissolution features in our study resemble reaction with subsolidus $\mathrm{C}-\mathrm{O}-\mathrm{H}$ fluids. The resorption style with deep etch pits (Fig. 1a), which characterises $30-50 \%$ of the studied diamonds with mantle-derived resorption best corresponds to dissolution in carbonate melt at temperatures above $1450^{\circ} \mathrm{C}$ and could represent mantle metasomatism by proto-kimberlite magma of carbonatitic composition. Instead, the whole range of observed dissolution morphologies could be produced by diamond reaction with silica-carbonate and 
carbonate melts of variable $\mathrm{SiO}_{2}$ content and temperature. Thus, our data show that at mantle conditions metasomatism by $\mathrm{C}-\mathrm{O}-\mathrm{H}$ fluid is not reactive to diamond, while melt-driven metasomatism causes diamond resorption. Our data support the recent proposal that diamond growth in harzburgitic mantle happens from subsolidus C-O-H fluid saturated in carbon (Stachel and Luth, 2015). The associated metasomatism by such a fluid would transform harzburgite into lherzolite as recorded in mantle garnets (Stachel et al. 2004, Griffin et al. 1999) depressing the temperature of the wet solidus (e.g. Wyllie, 1977). This could result in partial melting producing carbonate-rich melts. If carbon solubility in melts is higher than in C-O-H fluid, diamonds would start to dissolve and would develop resorption features. The depletion of the host mantle lithologies due to partial melting may then raise the solidus temperature and prevent further diamond dissolution. Repeating processes of fluid and melt metasomatism in the same mantle domain could explain the complex growth-dissolution patterns of mantle diamonds (Bulanova 1995). Thus, differences in carbon solubility in C-O-H fluid and carbonate-rich melts could control the balance between diamond growth vs. dissolution processes.
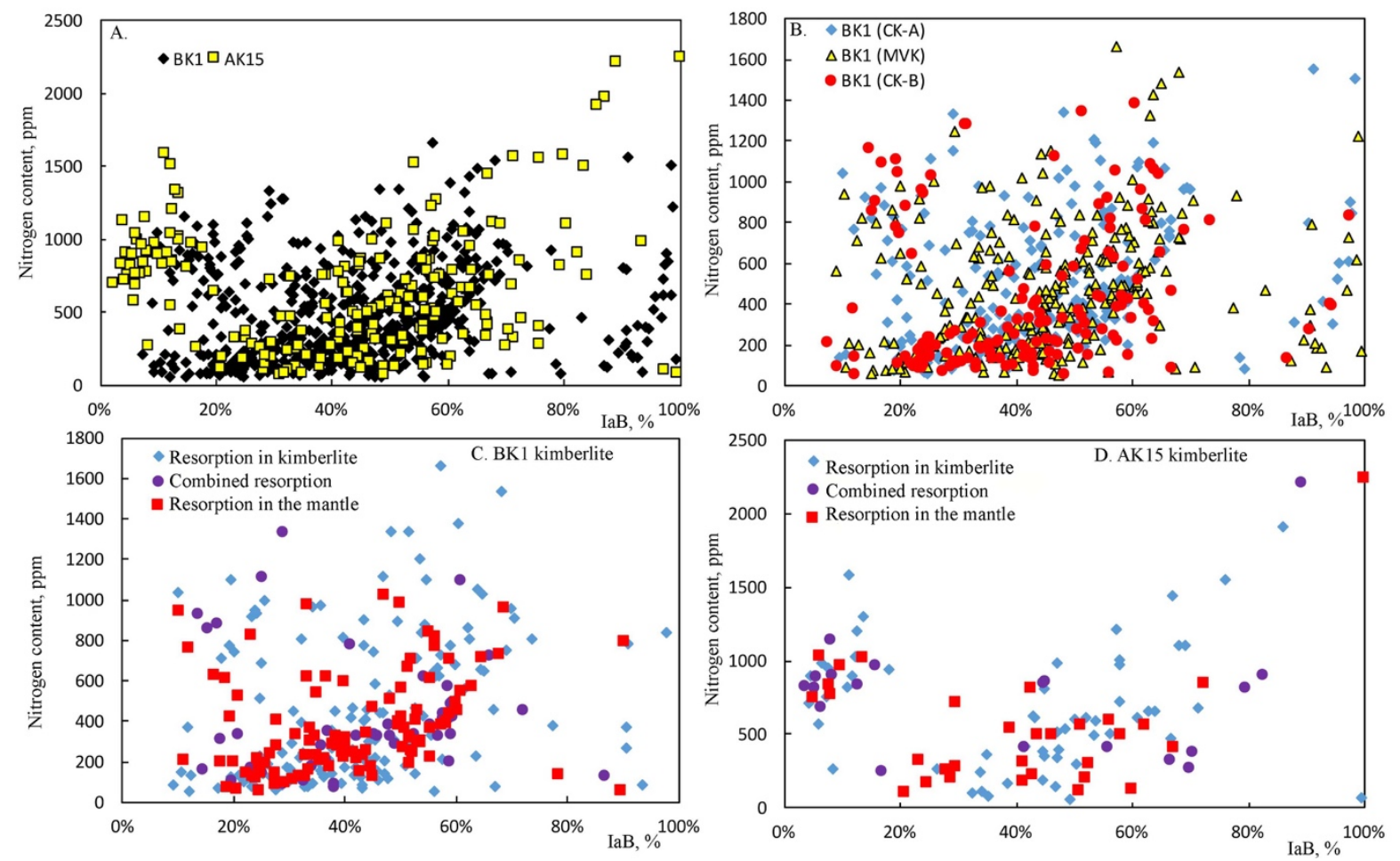

Figure 3: Nitrogen content vs aggregation state in diamonds A) from BK1 and AK15 kimberlites, B) from different lithologies of BK1 pipe, C, D) in diamonds with kimberlite-induced, mantle-derived and combined resoprtion.

\section{References}

Bulanova GP (1995) The formation of diamond. J. Geochem. Explor 53:1-23

Fedortchouk Y, Chinn IL, Kopylova MG (2017) Three styles of diamond resorption in a single kimberlite: Does crustal xenolith assimilation play a role? Abstract this volume No. 11IKC-4582

Griffin WL, Shee SR, Ryan CG, Win TT, Wyatt BA (1999) Harzburgite to lherzolite and back again: metasomatic processes in ultramafic xenoliths from the Wesselton kimberlite, Kimberley, South Africa. Contrib Mineral Petrol 134:232-250

Stachel T, Aulbach S, Brey GP, Harris JW, Leost I, Tappert R, Viljoen KS (2004) The trace element composition of silicate inclusions in diamonds: a review. Lithos 77:1-19

Stachel T, Luth RW (2015) Diamond formation - Where, when and how? Lithos 220-223:200-220

Wyllie PJ (1977) Mantle fluid compositions buffered by carbonates in peridotite- $\mathrm{CO}_{2}-\mathrm{H}_{2} \mathrm{O}$. Jour. Geology 85(2):187-207 